\title{
A Belo Horizonte do amanuense: a relação entre literatura e cidade no romance o Amanuense Belmiro
}

\author{
Alex Alves Fogal \\ Universidade Federal de Minas Gerais
}

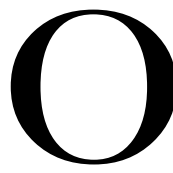

$s$ estudos que privilegiam as relações entre literatura e cidade deixam visível como a extrema complexidade da vida e a organização sócio-espacial configurada pela divisão do trabalho, fizeram com que os ficcionistas que de algum modo retrataram a cidade moderna, o fizessem de maneira que a reproduzissem como estilo. Ou seja, tornou-se inviável a representação da vida urbana como uma totalidade homogênea, pois tal objeto não pode mais ser visto como uma unidade, uma vez que sua estrutura apresenta sinais profundos de fragmentação e dinamismo.

A partir do momento em que o escritor toma essa consciência podese dizer que não se busca mais estabelecer um olhar de experiência objetiva sobre a cidade, mas sim focalizar as experiências mantidas em relação a essa. Aqui não se trata mais da cidade concreta, mas sim da idéia ou imagem construída a partir dela, colocando assim o conceito de representação como reconstrução de significado.

Tal reestruturação da imagem da cidade pelo viés da ficção se constitui como um dispositivo de suma importância, já que pretendo analisar no presente texto como tal processo de representação literária do espaço urbano ocorre entre a obra O Amanuense Belmiro (1937) do escritor 
mineiro Cyro dos Anjos e a cidade de Belo Horizonte. Tal investida privilegiará a capital mineira tal como narrada no romance pelo burocrata Belmiro Borba em suas andanças pelo centro e bairros da cidade, o que nos levará a uma perspectiva do espaço diferenciada, na qual a cidade não é vista apenas como um sistema urbano com suas casas, sua história, sua topografia e sua demografia. Meu objetivo será desenvolver algumas reflexões sobre a cidade moderna a partir de sua configuração no plano da ficção, focalizando sempre a narrativa de Cyro. O Amanuense Belmiro é fruto das crônicas de Cyro dos Anjos publicadas durante o ano de 1933 no jornal belo-horizontino chamado $A$ Tribuna sob o pseudônimo de Belmiro Borba, que depois viria a ser narrador-personagem do romance. O autor, nascido em Montes Claros, mas radicado em Belo Horizonte é autor de mais dois romances: Abdias (1945) e Montanha (1956). Contudo, o romance que narra a vida de um amanuense quase flâneur na cidade mineira durante os anos de 1935 e 1936 é considerada a principal obra de Cyro, uma vez que os outros dois romances adotam formas estéticas parecidas, mas que não foram desenvolvidas com o mesmo sucesso.

\section{2}

Como trato aqui da relação entre uma cidade e uma narrativa (ambas modernas) é importante ter em mente que no decorrer do século XVIII, a literatura foi incorporando cada vez mais a cidade como um de seus temas mais privilegiados, como se pode ver nas obras de Machado de Assis e Manuel Antônio de Almeida. Porém, foi a partir das transformações urbanas que viriam a acontecer nas primeiras décadas do século XX que essa incorporação foi se estruturando melhor. A cidade colonial brasileira, que sobreviveu até o início do século XX, tinha uma disposição demográfica e urbanística parecida com a cidade medieval européia e da cidade islâmica. Como tal, ela se caracteriza como um lócus fechado e restrito, que afastava os inimigos externos e se opunha à cidade atual, que deu lugar a uma ocupação extensiva, à tendência para o aglomerado populacional e a convivência com elementos distintos dentro do próprio limite da cidade moderna. Para Robert Moses: 
Durante todo o século XIX diferentes olhares se voltaram para a cidade no intuito de identificar e desvendar ali, por onde passavam as linhas do destino da civilização.

Assim, por exemplo, os romancistas são os primeiros a se darem conta de que o meio urbano, onde seus personagens se movimentam, é o cenário privilegiado para a observação do mundo. ${ }^{1}$

Assim como no caso do romance de Cyro, a visão do romancista identifica e reconstrói a cidade a partir da nova significação que atribui à sua estrutura e sua forma, já que é no âmbito citadino que se observa o desenrolar do drama da humanidade.

Antes de abordar o tema da cidade de Belo Horizonte em $O$ Amanuense Belmiro é importante ressaltar que as discussões sobre a cidade moderna são relevantes para falar da capital de Minas Gerais, pois esta foi toda planejada segundo os princípios racionais do novo urbanismo, diferentemente da maioria das cidades brasileiras daquela época. Mas, apesar dessa distinção de já ter nascido como uma cidade projetada, Belo Horizonte passou por um processo pelo qual várias outras cidades brasileiras também foram objeto, que foi o estabelecimento dos ideais republicanos de disciplina, ordem e higiene. Tal fenômeno ficou historicamente reconhecido como Belle Époque principalmente através dos exemplos de Rio de Janeiro, São Paulo, Salvador e teve como característica a influência das idéias e do gosto do neoclassicismo francês.

A imagem de Belo Horizonte como uma cidade moderna estava presente já em sua planta, pois o planejamento racional do espaço era evidente em franca oposição à ocupação do espaço ao acaso, se enquadrando no aspecto de cidade elaborada pelos preceitos do "ladrilhador" e não do "semeador", ou seja, demonstra o empenho em se sobrepor à natureza bruta e retificá-la, representando um ato definido da vontade humana, ao contrário da tendência de permitir que a forma do espaço tome caráter aleatório e desordenado, quase natural. ${ }^{2}$

\footnotetext{
${ }^{1}$ MOSES, 1994, p. 5.

${ }^{2}$ HOLANDA, 2008, p. 93-118.
} 
Em relação a essa questão da ordenação e domínio do espaço, é importante lembrar do barão Georges Eugéne Haussman, já que a reforma implementada por este em Paris é um marco inaugural da modernização urbanística, ${ }^{3}$ pois antes da reforma, a capital francesa apresentava um quadro urbano caótico, por causa das grandes transformações causadas pelo triunfo da economia capitalista na Europa. É opinião corrente entre os especialistas que até a metade do século XX o modelo de Haussman continuou predominando sobre algumas outras concepções de urbanização que haviam surgido na América Latina. ${ }^{4}$

Tais colocações são importantes para que não entendamos os fenômenos e processos de urbanização apenas como decorrência do desenvolvimento econômico ou transformaçôes na infra-estrutura das cidades, mas também como concatenados à mentalidade da época. Desse modo, a problemática urbana não pode ser apenas considerada como subproduto da industrialização e da modernização, já que olhar a questão desse ponto de vista não permite que se veja o espaço urbano fora do viés deformado pelas representaçôes ideológicas e institucionais assimiladas pelo processo de afirmação do capitalismo na história. $\mathrm{O}$ urbanismo, visto dessa maneira, pode ser entendido como a tentativa de submeter a realidade urbana à racionalidade, às exigências do mundo supostamente lógico sem contradiçóes ou conflitos estendendo ao conjunto das atividades sociais os pressupostos, intencionalidades e representaçōes da lógica fetichista. ${ }^{5} \mathrm{Um}$ olhar baseado em tais fundamentos reduz a vida urbana ao mínimo, fragmentando o objeto e dificultando sua apreensão. Para Lefebvre, esse olhar redutor não permite que o espaço urbano seja visualizado de modo que fuja às interpretaçôes preestabelecidas por essa estruturação rígida $\mathrm{e}$ normativa imposta pela racionalização do espaço na cidade moderna. ${ }^{6}$

${ }^{3}$ FOLLIS, 2004, p. 16-26.

${ }^{4}$ FOLLIS, 2004, p. 24-26.

${ }^{5}$ LEFEBVRE, 1999, p. 9-10.

${ }^{6}$ LEFEBVRE, 1999, p. 9-10. 
Uma alternativa para que se escape desse chamado olhar redutor limitado ao preestabelecido, é a visão da cidade a partir do ficcional, fazendo com que os escritores possam ressignificar o espaço urbano demonstrando que "o olhar percorre as ruas como se fossem páginas escritas". 7 A perspectiva literária acerca da cidade é capaz de gerar modos múltiplos de apreensão da imagem do espaço urbano, quebrando a lógica interpretativa rígida e limitada imposta pelo modo de organização do espaço urbano moderno, racionalizado e projetado. A cidade de Belo Horizonte, inaugurada em 1897, mas que teve sua construção estendida até a metade da década de $1910^{8}$ pode ser considerada um exemplo preciso dessa mentalidade. $O$ espaço urbano da capital mineira éo mundo menos vasto que o coração do narrador-personagem Belmiro, do romance de Cyro dos Anjos.

\section{3}

Cyro dos Anjos se insere no modernismo mineiro, ao lado de Abgar Renault, Carlos Drummond de Andrade, Emílio Moura, Pedro Nava, entre outros. O movimento modernista em Minas,como se sabe, teve um caráter bem diverso do que se pode observar no modernismo de 1922, já que seus membros não foram, como os paulistas, influenciados diretamente pelas vanguardas européias, o que resultou num movimento com tons mais tradicionalistas. A vertente belo-horizontina teve um dos seus maiores pontos de influência na visita de Mário de Andrade e seu grupo a Belo Horizonte em 1924. Tal fato é apontado por Drummond, que afirma ter sido após esse encontro que o modernismo mineiro consegue "seiva para se encorpar". ${ }^{9}$ Quanto à questão do caráter um pouco mais tradicional que o movimento demonstrou, é possível observar que

${ }^{7}$ CALVINO, 1990, p. 18.

${ }^{8}$ ANDRADE, 2004, p. 85.

${ }^{9}$ Drummond citado por ANDRADE, 2004, p. 90. 
até mesmo $A$ Revista, lançada em 1925 e considerada o principal instrumento de conquista da identidade modernista, apresenta caráter conciliatório em relação à tradição literária. ${ }^{10}$

Sabe-se que este movimento entre modernidade e tradição é inerente ao modernismo, ${ }^{11}$ no entanto, esse vínculo pode ser visto com mais nitidez no caso do movimento belo-horizontino. Uma possível explicação para tal questão é o fato de $A$ Revista não ter promovido uma ruptura no sentido estrito do termo, uma vez que não desafia totalmente o padrão literário vigente. Outro modo de entender o caráter mais passadista do movimento está relacionada ao contexto cultural do Estado, pois no período anterior ao modernismo em Minas Gerais, o número de produçōes literárias de grande importância foi pouco significativo. Houve apenas nomes isolados como Afonso Arinos, Bernardo Guimarães e Alphonsus de Guimaraens. ${ }^{12}$ Portanto, os modernistas mineiros não precisaram se opor violentamente a um passadismo literário já que não havia um movimento antecedente que fosse forte e bem estruturado.

Apesar desse relativo marasmo cultural observado na época, o contato com o ambiente da capital mineira foi de grande importância para o grupo, visto que a maioria dos participantes, com exceção de Austen Amaro, eram provenientes do interior. De acordo com Maria Zilda Ferreira Cury:

Neste caminho do Modernismo, internamente, o grupo vinha criando e usufruindo das condiçôes que propiciaram o processo de modernização de Belo Horizonte. Como se pode deduzir das páginas do DM, a cidade já gozava de um movimento cultural relativamente intenso. ${ }^{13}$

Esse movimento "relativamente" intenso que consta nas páginas do Diário de Minas, um dos mais importantes e influentes jornais da época,

\footnotetext{
${ }^{10}$ ANDRADE, 2004, p. 96.

${ }^{11}$ CURY, 1998, p. 85-101.

${ }^{12}$ ANDRADE, 2004, p. 97.

${ }^{13}$ CURY, 1998, p. 15.
} 
diz respeito ao caráter ainda provinciano da capital mineira no período. Conforme podemos notar no romance a partir do comentário de um dos amigos da roda de Belmiro, a cidade podia ser representada literariamente a partir desse aspecto: "Cidade besta, Belo Horizonte! Exclamou Redelvim, consultando o relógio. A gente não tem pra onde ir...". ${ }^{14}$

\section{4}

Após essas considerações sobre as questôes que atuam na relação da obra literária e a cidade é importante adentrar um pouco mais no romance de Cyro dos Anjos. Apesar do narrador se situar numa cidade que teve como projeto a racionalização do espaço, ele se mostra tomado por um forte apelo lírico e encontra sérias dificuldades em lidar com a razão prática no decorrer da obra. Para Antonio Candido, esse livro é:

como são em geral os livros dos escritores de Minas. Livros que lidam com os problemas do homem num tom de tal modo penetrante que autor e leitor se identificam, num admirável movimento de afinação. Não são livros que se imponham de fora para dentro, vibrantes, cheios de força. Insinuam-se lentamente na sensibilidade, até se identificarem com a nossa própria experiência. ${ }^{15}$

O crítico não foi o único a abordar esse subjetivismo fluido na literatura mineira e em Cyro. Muitos outros críticos como Rui Mourão, Laís Corrêa de Araújo e Fábio Lucas apontaram tal particularidade ao abordarem a literatura que os modernistas mineiros produziam. A criação literária desses autores é conceituada pela crítica como uma literatura que enfatiza o tempo e a memória como matéria privilegiada da narrativa, como vemos em Marcel Proust e já teve essa tendência intimista associada muitas vezes ao fato dos escritores de Minas Gerais viverem cercados de montanhas.

\footnotetext{
${ }^{14}$ ANJOS, 2001, p. 23

${ }^{15}$ CANDIDO, 2004, p. 79.
} 
No entanto, é relevante entender como essa predisposição ao intimismo pode ser relacionada à tendência de se escrever sobre o ambiente urbano, gerando um movimento duplo no romance de Cyro. Esta associação entre sentimento interior e a descrição exterior do mundo na narrativa de $O$ Amanuense Belmiro gera dois métodos de narrar no romance: um deles visível quando o narrador-personagem destaca suas impressões subjetivas sobre a cidade dando nova significação ao espaço; o outro ocorre nos momentos em que Belmiro Borba passeia pela cidade e a descreve de maneira mais objetiva e direta. É necessário deixar claro que esses métodos narrativos não podem ser vistos como bipolares ou antagônicos, mas sim como um método único, que, no entanto, se estrutura de maneira híbrida, mesclando dois movimentos em um só e fazendo com que o primeiro não possa ser definido como pura estilização pessoal e nem o segundo como estritamente descritivo e realista. ${ }^{16}$ Portanto, há um movimento duplo entre a narração que tem como base a expressão do subjetivo ou interno e a narração centrada na descrição daquilo que se apresenta como objetivo ou externo. As duas formas serão analisadas a seguir.

Em relação aos movimentos narrativos que apresentam tom lírico e intimista, observa-se que darão às impressões das ruas de Belo Horizonte um aspecto de prolongamento do mundo interior do narrador, fazendo com que esqueçamos a cidade real e fixemos a cidade representada por Belmiro. Essa perspectiva do amanuense, que não é nada racionalista, encontra-se em conflito com o espaço plenamente organizado da cidade moderna, buscando às vezes na memória as imagens necessárias quando o objeto visualizado não as oferece. $\mathrm{O}$ tipo de percepção exigido pela configuração do espaço urbano moderno de Belo Horizonte coloca-se desde o princípio em oposição à visão de mundo de Belmiro, pois para o protagonista "As coisas não estão no espaço leitor; as coisas estão é no tempo. Há nelas ilusória permanência de forma, que esconde uma desagregação constante, ainda que infinitesimal". ${ }^{17}$

${ }^{16}$ SCHWARZ, 2008, p. 12.

${ }^{17}$ ANJOS, 2001, p. 97. 
Na passagem citada acima se observa claramente a relação de Belmiro com o espaço. $\mathrm{O}$ burocrata lírico não é capaz de aceitar que os objetos concretos possam nos dizer mais que nossas impressōes, que muitas vezes buscamos na memória, no tempo. Em relação à Belo Horizonte do romance vista por essa perspectiva narrativa é isso que ocorre, já que não existe a possibilidade da cidade apresentar apenas um aspecto, já que a forma permanente das coisas é apenas ilusão.

Isto posto, é possível afirmar que, no plano romanesco, a forma provisória e ilusória da cidade fica expressa na visão do narrador quando esse, andando pelas ruas do centro de Belo Horizonte "inquieto como uma galinha sem ninho", ${ }^{18}$ procura um bonde para levá-lo até a casa de sua amiga Jandira. No meio do caminho, o amanuense escuta um sanfoneiro tocar despertando suas reminiscências. Belmiro, o lírico inveterado começa a seguir o sanfoneiro pelas ruas quando sente que seus passos o levavam "não para o cotidiano, mas para o tempo dos mortos". ${ }^{19}$ Nesse ponto da narrativa, fica visível como se dá a reconfiguração do espaço urbano a partir do olhar do amanuense, sempre estruturado pelos movimentos da memória e do sentimento íntimo. O narrador-personagem transforma a imagem da cidade que até então vinha descrevendo na representação da Vila Caraíbas, lugarejo onde ficaram suas lembranças familiares e seus primeiro amor, a falecida Camila. Belmiro nos mostra isso da seguinte forma: "Desci a Rua dos Guajajaras,com a alma e os olhos na Ladeira da Conceição,por onde, num bando alegre, passava Camila, tão leve, táo casta, depois da missa das nove, na igreja do Rosário". ${ }^{20}$

Esse olhar que ressignifica Belo Horizonte a partir da substância interior do narrador atravessará a obra, já que como foi dito acima, a descrição busca a imagem da cidade localizada no íntimo profundo do protagonista e não a cidade palpável, concreta. Tudo o que o personagem

\footnotetext{
${ }^{18}$ ANJOS, 2001, p. 33.

${ }^{19}$ ANJOS, 2001, p. 33.

${ }^{20}$ ANJOS, 2001, p. 33.
} 
narra sobre a cidade está intrinsecamente relacionado à questôes pessoais, fazendo assim com que o lirismo narrativo alcançado através da utilização do intimismo e da memória se torne um método de composição e permeie todas as relações do "eu" com o que lhe é exterior.

Nota-se dessa maneira que Belmiro, reconstruindo o significado das coisas concretas por meio de imagens subjetivas, busca restabelecer a unidade do externo com o interno, dando assim o tom lírico que sua narrativa possui. Ou seja, o lirismo narrativo permite que, quanto mais o amanuense mergulha em si mesmo, mais ele se torna capaz de atribuir forma ao mundo e vice-versa. Por exemplo,quando aborda a crescente industrialização de Belo Horizonte, relaciona essa questão ao seu sono de domingo, quase um ritual sagrado:

Os apitos das duas fábricas próximas (a da frente, que é de toalhas, e a que se acha por trás do lote vago, que é de calçados) sempre me despertam a tais horas. E a força do hábito faz com que aos domingos ou dias santos, embora não haja trabalho, eu acorde assustado, ouvindo qualquer apito do outro mundo.

Devo também esclarecer que engano os donos das fábricas reais e o da fábrica imaginária dos domingos: acabados os apitos, ponho-me de novo a dormir, embalado pela música das máquinas. ${ }^{21}$

Entretanto, apesar dessa ser a tendência geral dos movimentos de narração impressionista da cidade no romance, em alguns momentos pode-se notar também a narração um pouco mais descritiva e objetiva. Por exemplo, quando Belmiro narra sobre uma passagem no botequim de seu amigo Giovanni, o italiano que é seu vizinho na Rua Erê: "Fumase um cigarro. Comenta-se a batida dada na véspera, pela polícia, na macumba da Barroca. Prudêncio relata os pormenores. Depois, Giovanni, satisfeito, conta que o Prefeito novo vai melhorar muito o bairro do Prado". ${ }^{22}$

\footnotetext{
${ }^{21}$ ANJOS,2001, p. 104.

${ }^{22}$ ANJOS,2001, p. 117.
} 
Pode-se constatar também essa visão menos fundada - não deixa de ser subjetiva por isso - nas reminiscências e no intimismo de tom fortemente poético acerca da capital mineira, quando num fluxo narrativo de fôlego interrompido,bastante entrecortado, o amanuense descreve a igreja de São José e alguns cenários situados em seus arredores:

Finalmente, resolvo entre bocejos, dar um giro. Tomo o bonde, desço na Avenida. Homens e mulheres sobem a escadaria da igreja de São José. Por que não entraremos? Devo ou não, tirar o chapéu, em frente da igreja? O melhor é dar uma volta e não criar esse problema. Uma banda militar desce marcialmente a Rua da Bahia, rumo à Estação Central. Algum político importante deve estar a chegar. Ah! É verdade, o chefe da Seção pediu-me que comparecesse ao desembarque do Ministro. Ir, ou não ir, eis a questão. Qual, o melhor é irmos ao Parque ver as morenas que não nos verão. ${ }^{23}$

Nota-se que mesmo sem lançar mão do "método proustiano" de narrativa e se utilizando de um estilo que focaliza a descrição direta, o narrador deixa bem claro o estatuto ficcionalizante no qual atua, já que a utilização dos verbos "entraremos" e "irmos" mostra que o narrador faz questão da companhia de quem lê por esse "giro" pelas ruas e cenários de Belo Horizonte. A exatidão não é buscada, mas sim o prazer do passeio.

Esta satisfação proporcionada pela prática da perambulação que podemos notar no personagem do romance de Cyro pode ser vista como um traço flâneur em sua constituição. $\mathrm{O}$ amanuense literato mostra-se como um simpatizante da arte de "flanar", embora seja possível dizer que seja ainda um flâneur em potencial já que não é dotado de tanta desenvoltura como se observaria num típico representante dessa prática. Ainda assim, as caminhadas pela cidade, o contato com o ambiente urbano, sempre aparecem no romance de Cyro como solução para os momentos de tédio do burocrata lírico: "É preciso fazer qualquer coisa. Sobretudo tomar um sorvete, pois a noite está quente. Há na Avenida, um

${ }^{23}$ ANJOS, 2001, p. 135. 
bar que nunca se fecha. Aproveitemos a insônia e caminhemos um pouco". ${ }^{24}$ Pode-se observar que a primeira opção quando a insônia incomoda é caminhar, sair à procura de um bar que nunca se fecha.

Em passagens como esta, Belmiro se aproxima do método de perambular observável na obra Haxixe (1984) de Benjamin, ${ }^{25}$ onde o narrador realiza uma "flânerie" através das ruas de Marselha e constata que é possível encarar um mesmo objeto de duas maneiras distintas: como superfície imaginária ou como configuração linear,ou seja, de maneira essencialmente subjetiva tendo como fundamento as impressóes múltiplas acerca do objeto, ou de maneira mais ordenada, buscando uma linearidade. No entanto, percebe-se que, "as formas isoladas, integrando-se nos mais diferentes grupos, permitem quase sempre inúmeras configurações", ${ }^{26}$ demonstrando que não é possível estabelecer apenas um dos tipos de contato com o objeto. Assim ocorre com a narrativa de $O$ Amanuense Belmiro, já que na obra o "método intimista" e o "método descritivo" não podem ser vistos a partir de uma visão dicotômica, mas sim dialética.

A ressignificação que um tipo de narrativa como esse realiza em relação aos aspectos do espaço urbano nasce do vínculo entre a subjetividade e o mundo exterior, pois estabelecendo um paralelo com o que Sérgio Paulo Rouanet afirma sobre a questão da viagem do flâneur, pode-se dizer que ao percorrer a cidade, Belmiro "consegue uma iluminação profana, e com ela ilumina a própria cidade, desvendando-a em sua verdade alegórica". ${ }^{27}$ Ao iluminar e desvendar esse lado alegórico da capital, o narrador-personagem demonstra ter consciência do processo, o qual nos é revelado quando o amanuense reflete sobre a composição da narrativa. A citação é longa, mas ilustra de maneira adequada o que está sendo dito:

\footnotetext{
${ }^{24}$ ANJOS, 2001, p. 79.

${ }^{25}$ BENJAMIN, 1984, p. 15-37.

${ }^{26}$ BENJAMIN, 1984, p. 37.

${ }^{27}$ ROUANET, 1993, p. 10.
} 
"Nada me aconteceu de novo esta noite senão que, andando a esmo no Carlos Prates, ali pelos lados da Rua Serpentina, dei com uma roda morena. Assim chamavam na Vila, à roda alegre em que raparigas, braços dados, entoavam velhas modinhas. Uma ia ao centro do círculo, a cantar em solo, enquanto as outras faziam coro, no estribilho.

$\mathrm{E}$ as cantigas todas eram cantadas, sob o luar, até que o relógio da torre do Mercado desse suas nove horas que equivaliam ao toque de recolher. Minhas ruas e meus largos de Vila Caraíbas eram, assim, povoadas de ranchos femininos, que desprendiam beleza e inocência.

No momento preciso em que certos quadros se desdobram aos nosso olhos, quase sempre não lhes percebemos a intensidade lírica, nem lhes apreendemos a substância rica de poesia. Nosso olhar circula vago e às vezes indiferente. Mais tarde é que, através da memória, vamos com os olhos da alma penetrar no âmago daquelas paisagens extraordinárias". ${ }^{28}$

O trecho selecionado demonstra como Belmiro, andando a esmo pela capital, se vê diante de cenas que são provenientes da própria cidade, mas que ao passarem pelo crivo da consciência, momentos depois de assimiladas, tais imagens podem suscitar no indivíduo uma nova interpretação do espaço, aqui associado à sua saudosa Vila Caraíbas, como ocorre em outras passagens do romance. Nota-se que o movimento duplo observado na estrutura narrativa (descrição do exterior e expressão do interior), está relacionado a uma interpretação ambígua do espaço, na qual a cidade é associada à provinciana Vila Caraíbas.

Tal questão remete a um tema comum ao se falar da representação literária da cidade de Belo Horizonte nas décadas de 1920 e 1930, ${ }^{29}$ que é a mescla do aspecto moderno e racional da cidade e seu aspecto prosaico, interiorano. Observa-se que, embora a capital mineira da época fosse capaz de modernizar os tradicionais valores mineiros, tal mudança não ocorre efetivamente, pois a "mineiridade clássica sobrepôs-se aos valores modernos. ${ }^{30}$ Isso fez com que a cidade fosse retratada no plano da ficção

\footnotetext{
${ }^{28}$ ANJOS, 2001, p. 164.

${ }^{29}$ ALVES, 2002, p. 76.

${ }^{30}$ ALVES, 2002, p. 78.
} 
como um misto entre o moderno e o tradicional, uma mistura de urbano e interiorano. Se observarmos a impressão que esse dualismo causa em um dos contemporâneos de Cyro, Carlos Drummond de Andrade, veremos que para o poeta a tranqüilidade das noites mineiras é causa de um sentimento oposto, o de inquietação, ressaltando que o excesso de ordem e o marasmo das ruas e pessoas que nelas circulam o levem a perguntar: "Que fazer, para não morrer em paz?". 31

Esta visão sobre a Belo Horizonte da época pode ser constatada também na visão do amanuense quando este contempla Belo Horizonte do alto de uma colina, no Morro dos Pintos:

Subindo a Rua Erê, tomei à esquerda a Rua Diábase, que, mais para o alto, recebe o nome de Esmeralda. Segui-a até o fim e, pela estrada que a continua, cheguei ao Morro dos Pintos. Do alto da colina, contemplei Belo Horizonte, que apenas despertava. As cores, já vivas, do céu e a luminosa beleza da cidade feriram-me os olhos. Esses palácios e jardins e a majestade das avenidas e praças situam Belo Horizonte fora dos quadros singelos de Minas. Dentro das casas mora, porém,o mesmo e venerável espírito de Sabarabuçu, Tejuco, Ouro Preto e de tantas outras vetustas cidades. Penso no homem mineiro que se levanta, lê seu Minas Gerais, cuida dos passarinhos e se prepara, tranqüilo, para as labutas do dia. ${ }^{32}$

Essa peculiaridade da cidade no momento enfocado é resultado da migração da população proveniente do interior do Estado como, por exemplo, os funcionários púbicos que vinham preencher os cargos burocráticos, os operários destinados a trabalharem na construção civil e os comerciantes instalados na capital. Tais indivíduos não possuíam uma mentalidade ou sensibilidade próprias da modernidade que a cidade representava. ${ }^{33}$

${ }^{31}$ ANDRADE, 1983, p. 576.

${ }^{32}$ ANJOS, 2001, p. 115.

${ }^{33}$ ANDRADE, 2004, p. 77. 
Nota-se que as relações entre as imagens proporcionadas pela ficção e as que a realidade nos apresenta proporcionam possibilidades múltiplas de reinterpretação do espaço físico social de Belo Horizonte, já que algumas vezes convergem e noutros divergem.

Meu interesse nesse artigo foi avaliar tal questão, partindo de uma obra literária específica que permite a visão ampla da relação entre o universo literário e extra-literário, numa perspectiva de análise próxima do que Leopoldo Waizbort chama de "mimesis dialética", onde o sentido "dessa dialética é possibilitar a transmutação, de sorte que a realidade da obra de arte não é menor, nem pior, do que a realidade informada pela estrutura social entendida em sua totalidade. ${ }^{34}$

Assim sendo, tentei privilegiar nas relaçóes entre a cidade real e sua representação romanesca, uma visão a partir da qual a experiência criadora, o imaginário, busca sua matéria no real, inspira-se nele, mas considerando essa inspiração não como dependência, mas sim dentro da noção de representação e ressignificação. Busquei compreender a expressão literária como linguagem que não necessita negar o mundo para inovar,mas sim o atualiza, privilegiando sempre o conceito de que o imaginário não deve ser entendido como violência ao real, mas sim como marcador da mediação de uma outra realidade. Desse modo, pode-se entender que entre a estética e vida pode ser vista uma distância, mas não uma separação. ${ }^{35}$

Portanto, a partir da análise aqui empreendida para estudar a relação entre $O$ Amanuense Belmiro e a cidade de Belo-Horizonte, é possível entender os escritores como leitores do espaço construído, já que dão voz ao que aparenta ser apenas construção de concreto e metal, nos permitindo entender o espaço como algo dotado de sentido, ou melhor, sentidos.

\footnotetext{
${ }^{34}$ WAIZBORT, 2007, p. 24.

${ }^{35}$ MERQUIOR, 1996, p. 250.
} 


\section{Referências bibliográficas}

ANDRADE, Carlos Drummond de. Carlos Drummond de Andrade: poesia e prosa. 5. ed. Rio de Janeiro: Nova Aguilar, 1983.

ANDRADE, Luciana Teixeira. A Belo-Horizonte dos Modernistas: representações ambivalentes da cidade moderna. Belo Horizonte: Puc Minas; C/ Arte, 2004.

ANJOS, Cyro dos. O Amanuense Belmiro. 16. ed. Belo Horizonte: Livraria Garnier, 2001.

ALVES, Liliane da Silva. O imaginário literário de Belo-Horizonte. 202. Dissertação (Mestrado) - Faculdade de Letras, Universidade Federal de Minas Gerais, Belo Horizonte, 2002.

BENJAMIN, Walter. Haxixe. São Paulo: Editora Brasiliense, 1984.

CALVINO, Ítalo. As cidades invisiveis. São Paulo: Companhia das Letras, 1990.

CANDIDO, Antonio. Brigada Ligeira. 3. ed. Rio de Janeiro: Ouro Sobre Azul, 2004.

CURY, Maria Zilda Ferreira. Horizontes Modernistas: o jovem Drummond e seu grupo em papel jornal. Belo Horizonte: Autêntica, 1998.

FOLLIS, Fransérgio. Modernização urbana na Belle Époque paulista. São Paulo: Editora Unesp, 2004.

HOLANDA, Sérgio Buarque de. Raízes do Brasil. 26. ed. São Paulo: Companhia das Letras, 1995.

LEFEBVRE, Henri. A Revolução Urbana. Belo-Horizonte: Ed. UFMG, 1999.

MERQUIOR, José Guilherme. Razão do Poema. 2. ed. Rio de Janeiro: Topbooks, 1996.

PECHMAN, Robert Moses (Org.). Olhares sobre a cidade. Rio de Janeiro: Ed. UFRJ,1994.

ROUANET. Sergio Paulo. A razão nômade. Rio de Janeiro: Ed. UFRJ, 1993.

SCHWARZ, Roberto. O pai de familia e outros estudos. 2. ed. São Paulo: Companhia das Letras, 2008.

WAIZBORT, Leopoldo. A passagem do três ao um: crítica literária, sociologia, filologia. São Paulo: Cosac Naify, 2007. 


\section{Resumo}

Este artigo visa analisar as relações entre literatura e cidade a partir da análise da idéia ou imagem dessa considerando sua construção no plano literário, o que significa que não será enfocada aqui a cidade empírica, concreta, mas sim o espaço urbano como reconstrução de significado a partir do plano ficcional. Meu interesse nesse artigo foi analisar esse tipo de representação no caso de Belo Horizonte, partindo de uma obra literária específica que permite a visão ampla da relação entre o universo literário e o extra-literário. A obra escolhida foi o romance O Amanuense Belmiro do escritor Cyro dos Anjos, que possui como cenário a capital mineira.

\section{Abstract}

This article tries to analyse the relations between literature and the city by the point of view that consider the idea or image of the urban space as a ficcional construction, what means that will be not emphasized the empirical city, but the urban space as a reconstruction of mean trough the literature. My interest at this article was to analyse this kind of representation in the case of Belo Horizonte, pointing a especifical literary production that allow a broad view of the relation between the literary universe and the extra-literary universe. The chosen romance was the book O Amanuense Belmiro writed by Cyro dos Anjos. The narrative has the capital of Minas Gerais as scene. 